\title{
Maternal and perinatal outcome in pregnancy beyond expected date of delivery
}

\author{
Golait S. ${ }^{1}$, Soni S. ${ }^{2}$ \\ ${ }^{1}$ Dr. Shakti Golait, PG Medical Officer, JP Hospital, Bhopal, ${ }^{2}$ Dr. Sona Soni, Department of Obstetrics \& Gynae, GMC, \\ Bhopal, MP, India.
}

Corresponding Author: Dr. Sona Soni, Assistant Professor, Department of Obstetrics \& Gynae, GMC, Bhopal. E-mail: sonasoni0123@gmail.com

\begin{abstract}
Aim: To assess the maternal and perinatal outcome in pregnancy beyond EDD up to 42 weeks and to assess incidence of intervention, instrumental or operative delivery. Instrumentation intervention or operative intervention. Methods. The study consisting of 100 cases of pregnancy between 40-41 weeks and 100 cases of pregnancy 41-42 weeks of gestation design as a group I and group II. Results It was seen that $20 \%$ of the cases and $08 \%$ of cases underwent spontaneous labour in group I \& II, $16 \%$ \& $20 \%$ cases underwent induced labour type of labour significantly associated with gestation age. $64 \%$ of the cases underwent LSCS compare to the $78 \%$ of the cases underwent LSCS in group II. MSL present $17 \%$ and $22 \%$ in group I and group II respectively. MAS present in $17.64 \%$ and $31.87 \%$ in group I and group II respectively. Birth asphyxia present $5.88 \%$ and $9.09 \%$ in group I and group II respectively. Fetal distress $6 \%$ and $7 \%$ group I and group II respectively. NICU admission $17.64 \%$ and $13.8 \%$ in group I and group II respectively. Birth weight more than $2.5 \mathrm{~kg}$ in 32 cases and 65 cases in group I \& II. Prolonged pregnancy associated with primigravida $60 \%$ in group I and $56 \%$ in group II. Macrosomia found 5\% in group I and 13\% in group II. Conclusion: Reduction in perinatal mortality is seen when caesarean section is done between 41 weeks and 42 weeks. Perinatal morbidity has also been noted to be higher in post term pregnancies including meconium and meconium aspiration syndrome.
\end{abstract}

Keywords: Perinatal morbidity, Postterm pregnancies, Meconium aspiration syndrome, EDD [Expected Date of Delivery]

\section{Introduction}

Smooth expectation labour is the cherished dream of every pregnant woman. Postterm pregnancy has been defined as a pregnancy that persists beyond 294 days or 42 weeks of gestation. The postterm pregnancy, which likely occurs among less than $5 \%$ of gravidas has been associated with an increased perinatal mortality rate. [1]

Galal M, Symonds I et al found that the incidence of stillbirth increases from 39 weeks onwards with a sharp rise after 40 weeks of gestation. Induction of labour before 42 weeks of gestation has the potential to prevent these complications; however, both patients and clinicians alike are concerned about risks associated with induction of labour such as failure of induction and increases in CS rates. There is a strong body of evidence however that demonstrates that induction of

Manuscript received: $30^{\text {th }}$ May 2019

Reviewed: $10^{\text {th }}$ June 2019

Author Corrected: $17^{\text {th }}$ June 2019
Accepted for Publication: $21^{\text {st }}$ June 2019

labour at term and prior to 42 weeks of gestation (particularly between 40 and 42 weeks) is associated with a reduction in perinatal complications without an associated increase in CS rates. Therefore they postulated a policy of induction of labour at 41 weeks in postterm women could be beneficial with potential improvement in perinatal outcome and a reduction in maternal complications [2].

Perinatal morbidity has also been noted to be higher in post term pregnancies including meconium and meconium aspiration syndrome, oligohydramnios, macrosomia, fetal birth injury, rate of non-reassuring fetal heart rate or fetal distress in labor, and rates of cesarean delivery.

While it is well established that these risks are increased in post term pregnancy, what is less well elucidated is 


\section{Original Research Article}

whether these risks increase prior to 42 weeks' gestation $[3,4,5]$.

Risk of adverse perinatal and maternal outcome increases with increasing gestational age beyond term. To be expelled timely from the uterus is almost as important as to be nourished perfectly in it. To be born too late is likely to be disastrous.

The prolongation of pregnancy beyond 40 weeks occurs frequently that is 1 in every 10 pregnancies.Perinatal mortality and morbidity are increased in prolong pregnancy, perinatal mortality is two to three times in these prolonged gestation.

Fetal mortality in pregnancies that exceed 41 weeks in length is almost doubled than that seen in patients who delivered between 40 to 41 weeks.

Most obstetricians would in consequence elect to deliver their patients before 42 weeks of pregnancy were completed $[6,7,8,9]$.

Considering the anxiety of patients and obstetrician and a tendency to induce beyond expected date of delivery this topic is taken to study the outcome of pregnancy, which has crossed the expected date of delivery.

\section{Methodology}

Study setting: Primi or multi admitted in labour room of department of Obst. \& Gynae at KRH, G.R.M.C., Gwalior over a period of 15 months.

Study subjects: Study has been carried out of 100 patients randomly selected with pregnancy beyond the EDD upto 42 weeks irrespective of any gravidae.

Sample size: 100 patients randomly selected with pregnancy beyond the EDD upto 42 weeks

Data collection: Study has been carried out of 100 patients randomly selected with pregnancy beyond the EDD upto 42 weeks irrespective of any gravidae. Primi or multi admitted in labour room of department of Obst. \& Gynae at KRH, G.R.M.C., Gwalior.

\section{Inclusion Criteria}

- Low risk primi or multi whose LMP definitely known

- Menstrual cycle regular

- EDD crossed of upto 2 weeks.

- The presentation must be vertex.
- Single ton intrauterine pregnancy.

- EDD was calculated as per Naegles formula.

Exclusion Criteria

- Pregnant woman who is chronic hypertensive.

- Preclampsia

- Pre existing diabetes

- Multiple gestation

- Non vertex presentation

- No ANC visit

\section{Limitation}

- The study was done for limited period so it reflects the aptitude of that period only.

- Many patients did not follow up regularly during ANC and came directly during labor after crossing the expected date of delivery.

Management protocol on admission: Proctolysis enema was given to most of patients on admission. Patients who were admitted for induction were induced with prostaglandin E2 (cerviprime) gel intracervically or prostaglandin E1 and analogue tablet intravaginally after taking written and informed consent.

Patient who were admitted with spontaneous labour were monitored for fetal heart rate, artificial rupture of membranes was done in active phase of labor.

Patients with meconium stained liquor stat LSCS. If required labor was augmented with oxytocin.

The follow-up of the mother was done in the following lines.

- Induction / Spontaneous Labor

- Mode of delivery

1. Vaginal delivery

2. LSCS

3. Instrumental delivery

- Duration of Labor

- Colour of the liquor

The follow-up of the babies was done and following were noted.

Apgar Score1 Min and 5 Min, Weight, Sign of meconium aspiration, Sign of birth asphyxia, NICU 
admission, Sign of hypoxic ischaemic encephalopathy, Perinatal Mortality, Evidence of birth trauma, S.B., Low birth weight baby were noted

\section{Results}

Table-1: Parity wise distribution of cases.

\begin{tabular}{|c|c|c|c|c|c|}
\hline \multirow{2}{*}{$\begin{array}{c}\text { Gestational } \\
\text { age (wks) }\end{array}$} & \multicolumn{2}{|c|}{ Primi } & \multicolumn{2}{c|}{ Multi } & \multirow{2}{*}{ Total } \\
\cline { 2 - 5 } & Number & $\%$ & Number & \% & 100 \\
\hline $40-41$ & 60 & 60 & 40 & 40 & 100 \\
\hline $41-42$ & 56 & 56 & 44 & 44 & \\
\hline
\end{tabular}

The above table shows the comparison of parity in group I and group II.

$$
\chi^{2}=5.13, \quad \mathrm{DF}=1, \quad \mathrm{p}=0.025
$$

In this study 60 cases are primi gravida and 40 cases are multi gravida in group I compared with the group II were 56 cases are primi gravida and 44 cases are multi gravida which is statistically significant prolonged pregnancy more frequently associated in Primi than Multiparous.

Table No.-2: Delivery outcome in different modalities of labour.

\begin{tabular}{|c|c|c|c|c|c|}
\hline \multicolumn{2}{|c|}{ Spontaneous } & \multicolumn{2}{c|}{ Induced } & \multicolumn{2}{c|}{ Converted LSCS } \\
\hline $\begin{array}{c}\mathbf{4 0 - 4 1} \text { weeks } \\
\mathbf{n = 1 0 0}\end{array}$ & $\begin{array}{c}\mathbf{4 1 - 4 2} \text { weeks } \\
\mathbf{n = 1 0 0}\end{array}$ & $\begin{array}{c}\mathbf{4 0 - 4 1} \text { weeks } \\
\mathbf{n = 2 5}\end{array}$ & $\begin{array}{c}\mathbf{4 1 - 4 2} \text { weeks } \\
\mathbf{n}=\mathbf{3 2}\end{array}$ & $\mathbf{4 0 - 4 1}$ weeks & $\mathbf{4 1 - 4 2}$ weeks \\
\hline 20 & 8 & 16 & 20 & 9 & 12 \\
\hline
\end{tabular}

Study shows in group I (40-41weeks) 25 cases are induced out of these 16 cases undergo normal delivery and 9 cases underwent LSCS. Similarly in group II (41-42weeks) 32 cases are induced in which 20 cases undergo normal delivery and 12 cases underwent LSCS.

Rate of LSCS higher in group II i.e. $72 \%$ where as in group I rate of LSCS was $64 \%$.Statistically significant higher rate of LSCS.

Table-3: Type of labour.

\begin{tabular}{|c|c|c|c|c|}
\hline \multirow{2}{*}{ Type } & \multicolumn{2}{|c|}{$\mathbf{4 0 - 4 1}$ weeks, $\mathbf{n = 1 0 0}$} & \multicolumn{2}{|c|}{$\mathbf{4 1 - 4 2}$ weeks, $\mathbf{n = 1 0 0}$} \\
\cline { 2 - 5 } & Number & $\mathbf{\%}$ & Number & \% \\
\hline Spontaneous & 20 & 20.0 & 08 & 8.0 \\
\hline Induced & 16 & 16.0 & 20 & 20.0 \\
\hline LSCS & 64 & 64.0 & 72 & 72.0 \\
\hline
\end{tabular}

$\chi^{2}=4.66, \quad \mathrm{p}=0.03$

Type of the labour significantly associated with weeks of gestation p value 0.03 (less than 0.05 ). Incidence of LSCS increases with increasing gestational age.

Table-4: Incidence of Fetal distress.

\begin{tabular}{|c|c|c|c|c|}
\hline \multirow{2}{*}{ Gestational age (weeks) } & \multicolumn{4}{|c|}{ No. of cases } \\
\cline { 2 - 5 } & \multicolumn{2}{|c|}{ Present } & \multicolumn{2}{c|}{ Absent } \\
\cline { 2 - 5 } & Number & Number & \% \\
\hline $40-41$ N-100 & 06 & 06 & 94 & 94 \\
\hline $41-42$ N-100 & 17 & 17 & 83 & 83 \\
\hline
\end{tabular}

$\chi^{2}=5.264, \quad \mathrm{p}=0.021$ 
The above table shows incidence of fetal distress $6 \%$ in group I and $17 \%$ in group II respectively. This difference is statistically significant because fetal distress increases with gestational age.

Table-5: Gestational week wise incidence of Meconium Aspiration Syndrome (MAS).

\begin{tabular}{|c|c|c|c|c|c|}
\hline \multirow{2}{*}{$\begin{array}{c}\text { Gestational age } \\
\text { (weeks) }\end{array}$} & \multirow{2}{*}{$\begin{array}{c}\text { Total no. of cases with } \\
\text { MSL }\end{array}$} & \multicolumn{4}{|c|}{ No. of MAS } \\
\cline { 3 - 6 } & & \multicolumn{2}{|c|}{ Present } & \multicolumn{2}{c|}{ Absent } \\
\cline { 3 - 6 } & & Number & $\%$ & Number & 81.0 \\
\hline $40-41$ & 16 & 03 & 18.7 & 13 & 68.18 \\
\hline $41-42$ & 22 & 07 & 31.85 & 15 & $\%$ \\
\hline
\end{tabular}

$\chi^{2}=5.01$

$\mathrm{p}=0.025$

The rate of meconium Aspiration syndrome increases with increasing gestational age and it is statically significant.

Table-6: Relationship of weeks of gestation to NICU admission

\begin{tabular}{|c|c|c|c|c|c|}
\hline Gestational (weeks) & \multirow{2}{*}{$\begin{array}{c}\text { No. of cases with } \\
\text { MSL }\end{array}$} & \multicolumn{4}{|c|}{ No. of NICU admission } \\
\cline { 3 - 6 } & & \multicolumn{2}{|c|}{ Present } & \multicolumn{3}{c|}{ Absent } \\
\cline { 3 - 6 } & & Number & 18.75 & 13 & 81.25 \\
\hline $40-41$ & 16 & 03 & 31.81 & 15 & 68.18 \\
\hline $41-42$ & 22 & 07 & Number & $\%$ \\
\hline
\end{tabular}

Further analysis of NICU admission increases with increasing the gestation age show in table.

Table-7: Birth weight of Neonates.

\begin{tabular}{|c|c|c|c|c|}
\hline \multirow{2}{*}{ Weight (kg) } & \multicolumn{2}{|c|}{$\begin{array}{c}\text { 40-41 weeks } \\
\text { n=100 }\end{array}$} & \multicolumn{2}{c|}{$\begin{array}{c}\text { 41-42 weeks } \\
\text { n=100 }\end{array}$} \\
\cline { 2 - 5 } & Number & \% & Number & 03 \\
\hline$<2.5$ & 52 & 52 & 03 & 65 \\
\hline $2.6-3$ & 32 & 32 & 65 & 19 \\
\hline $3.1-3.5$ & 11 & 11 & 19 & 13 \\
\hline $3.6-4$ & 05 & 05 & 13 & 0 \\
\hline
\end{tabular}

$\chi^{2}=6.05, \quad \mathrm{DF}=3 \quad \mathrm{p}=0.0001$

There are statistically significant difference between the birth weight in respect to gestation age in group I and group II respectively.

The study was conducted in K.R.H. associated with J.A. Group of Hospitals, in G.R.M.C., Gwalior (M.P.) over a period of 15 months. Following results were obtained from the present study:

- Maximum number of patients age group 21-25 years in both study group (study group I pregnancy with gestational age 40-41 weeks and study group II pregnancy with gestational age 41-42 weeks).

- In the present study maximum patients were primi parous it showed that prolonged pregnancy is more frequently associated with primi parity.

- The present study showed that incidence of LSCS increased with increasing gestational age.

- In the present study after induction most of the patients got delivered vaginally.

- The present study also showed that risk of fetal distress increased with gestational age because of increased chances of meconium stained liquor which increases with gestational age.

- Because of increased risk of meconium aspiration, NICU admission rate increases with gestational age. 
- SOGC published clinical practical guideline recommending that women with an uncomplicated pregnancy who reaches 41 to 42 weeks of gestation increase the rate of intervention.

\section{Discussion}

The study showed incidence of MSL increases by $17 \%$ in group $\mathrm{I}$ and $28 \%$ in group II. There is also concomitant increases in birth asphyxia and requiring ventilation. Perinatal mortality associated with fetal distress MAL, MAS \& birth asphyxia. Authors suggest that with very high accuracy of gestational age all patients passed EDD should be followed requiring strict antenatal fetal surveillance, intrapartum fetal surveillance, these patients should be induced at earliest before any sign of fetal compromise, irrespective of bishop score.

Magram HM et al did a statistical analysis to the problem of post maturity.Analysis of 6,235 consecutive deliveries showed that 274 or 4.4 per cent were prolonged beyond 301 days. Comparison of these 274 patients with the group delivering at term showed: (1) there was no difference in age, race, or parity; (2) no special risks were encountered by the patient of advanced age or by the elderly primigravida; (3) there was no increase in perinatal mortality in the postmature patients; (4) the duration of labor and the number of spontaneous deliveries was about the same; (5) there was, however, a small but significant increase in weight of the overdue baby; (6) there was quite a significant increase in fetal distress, both in the multigravida and in the primigravida; and (7) there was a threefold increase in cesarean sections after the onset of labor in prolonged pregnancy.[10]

Lagrew DC, Freeman RK et al in their study on management of postdate pregnancy dealt with problems associated with pregnancies that extend beyond 294 days of amenorrhea outlines some of the methods that minimize the risks to the mother, fetus, and neonate in postdate pregnancy. Finally they gave a synopsis of research areas that may change management[11].

Gardosi J, Vanner T did their study with the objective to examine the length of gestation according to menstrual and ultrasound scan dates, and the rate of induction of labour in a unit with a routine induction policy for prolonged pregnancy.

The single largest category of reasons given for induction of labour was prolonged pregnancy. 'Post-term pregnancy', from the date of expected delivery as recorded in the notes, together with 'maternal request' and 'social factors', were the reasons given for induction of labour in $71.3 \%$ of cases. Menstrual dates systematically overestimated

gestational age at term when compared with scan dates. After 41 weeks, this difference exceeded the confidence limits for second trimester scan dating error, suggesting that most pregnancies which are considered 'prolonged' according to menstrual dates are in fact mis-dated. Most pregnancies undergoing post-term induction are not post-term when assessed by ultrasound dates.

Regardless of whether prolonged pregnancy is considered to be a risk factor requiring intervention, the proportion of pregnancies considered 'post-term' can be reduced considerably by a dating policy which ignores menstrual dates and establishes the expected delivery date on the basis of ultrasound dates alone[12].

Crowley $\mathrm{P}$ studied interventions for preventing or improving the outcome of delivery at or beyond term. Perinatal mortality and morbidity is increased in pregnancies of more than 42 weeks that are otherwise low risk. The objective of this review was to assess the effects of interventions aimed at either reducing the incidence or improving the outcome of post-term pregnancy. There were four trials of routine early pregnancy ultrasound, two of nipple stimulation, nineteen of routine versus selective induction of labour and one of antenatal fetal monitoring.

Routine early pregnancy ultrasound reduced the incidence of post-term pregnancy (odds ratio 0.68, 95\% confidence interval 0.57 to 0.82 ). Routine early pregnancy ultrasound examination and subsequent adjustment of delivery date appear to reduce the incidence of post-term pregnancy. Routine induction of labour after 41 weeks gestation appears to reduce perinatal mortality. There is not enough evidence to evaluate the effects of breast and nipple stimulation, or tests of fetal wellbeing [13].

Cleary-Goldman J, Malone FD et al studied impact of maternal age on obstetric outcome. The objective was to estimate the effect of maternal age on obstetric outcomes. A prospective database from a multicenter investigation of singletons, the FASTER trial, was studied. Subjects were divided into 3 age groups: 1) less than 35 years, 2) 35-39 years, and 3) 40 years and older. Multivariable logistic regression analysis was used to assess the effect of age on outcomes after 
adjusting for race, parity, body mass index, education, marital status, smoking, medical history, use of assisted conception, and patient's study site.Increasing maternal age is independently associated with specific adverse pregnancy outcomes. Increasing age is a continuum rather than a threshold effect [14]. The burning question here is When Should We Intervene? Norwitz ER et al suggest that the timely onset of labor and birth is an important determinant of perinatal outcome. Prolonged (postterm) pregnancy - defined as delivery at or beyond 42 weeks' gestation - complicates $10 \%$ of all gestations and is associated with increased risks to both fetus and mother. The risk of routine induction of labor in the era of cervical ripening is lower than previously reported. For these reasons, the authors favor a policy of routine induction of labor for low-risk pregnancies at 41 weeks' gestation [15].

Doherty L, Norwitz ER et al alsosuggested that prolonged pregnancies are associated with both fetal and maternal complications. A variety of management practices can be utilized to mitigate the risk of these complications. A number of alternative management strategies show promise in preventing adverse fetal outcomes.

The routine use of ultrasonography for pregnancy dating lowers the rate of postterm pregnancy and is associated with less need for induction of labor. In the era of cervical ripening, routine induction of labor at 41 weeks does not increase the overall cesarean delivery rate. The authors favor routine induction of labor at 41 weeks in women with low-risk singleton gestations [16].

Complementary therapies in clinical practice for postdate pregnancy was studied by Evans M. Their paper explores the contribution of self-help techniques and complementary therapies within the management of postdates pregnancy. The most common reason for induction of labour is postdates pregnancy and not as one would imagine, associated with complex cases that would result in fetal or maternal morbidity without timely intervention.

Induction of labour is not without its risks and may well contribute to iatrogenic complications when used more widely and in normal, unwarranted cases. The role of self-help techniques and the safe use of complementary therapies is critically explored within a model of enhancing hormonal activity and reduction of stress hormones during the postdates period, in conjunction with a more conservative approach of care for uncomplicated postdates pregnancy[17]. Comparison of antepartum testing schemes for the management of the postdate pregnancy was done by Eden RD et al. They analyzed the outcome results of 583 postdate pregnancies managed prospectively by one of three antepartum testing schemes, each predicated on the nonstress test. In scheme 1, they relied upon the contraction stress test for evaluation of the nonreactive non-stress test. In scheme 2, they used a modified biophysical profile to evaluate the nonreactive non-stress test. In addition, patients were tested semiweekly. In scheme 3, they added routine weekly ultrasound evaluation of amniotic fluid volume to scheme 2. Only in scheme 3 did they induce labor for decreased amniotic fluid volume or fetal cardiac decelerations irrespective of reactivity.

The incidence of fetal distress, perinatal mortality, and perinatal morbidity was increased in babies with decelerations or decreased amniotic fluid volume. These results suggest a benefit to both semiweekly testing and liberalized criteria for intervention in postdate pregnancies.

They also compared the outcome results of scheme 3 with those reported for schemes in which the weekly contraction stress test was used as the primary form of surveillance. They found the outcome results comparable in that both schemes showed minimal mortality and morbidity statistics but high intervention rates $(25 \%$ to $30 \%)$ [18].

Alexander $\mathrm{J}$ Metal in their study forty weeks and beyond in which they studied pregnancy outcomes by week of gestation when labor induction is done routinely at 42 but not 41 weeks. They excluded women with hypertension, prior cesarean, diabetes, malformations, breech presentation, and placenta previa. Labor characteristics and neonatal outcomes of pregnancies at 41 and 42 weeks' gestation were compared with pregnancies that ended at 40 weeks. Women with certain dating criteria had induction of labor at 42 weeks.

Gestational age was calculated from the last menstrual period (LMP), sonography when available, and clinical examination. They concluded that routine labor induction at 41 weeks likely increases labor complications and operative delivery without significantly improving neonatal outcome [19].

Hilder L, Costeloe $\mathrm{K}$ et al evaluated gestation-specific risks of stillbirth, neonatal and post-neonatal mortality. 


\section{Original Research Article}

Main outcome measures were the incidence of births, stillbirths, neonatal and post-neonatal deaths at each gestation after 28 completed weeks. Mortality rates per 1000 total or live births and per 1000 ongoing pregnancies at each gestation were calculated. The risks of prolonged gestation on pregnancy are better reflected by calculating fetal and infant losses per 1000 ongoing pregnancies. There is a significant increase in the risk of stillbirth, neonatal and post-neonatal mortality in prolonged pregnancy. This study provided accurate data on gestation-specific risks of pregnancy loss, enabling pregnant women and their careers to judge the appropriateness of obstetric intervention [20].

In the present study the adverse effects of post term pregnancy are seen mainly in primigravidae and the small size of the sample did not allow separate analysis of primipara and multipara. A large sample prospective study needed to draw conclusions to generalize the results on a national basis.

In summary, post term pregnancy is associated with increased risks to both mother (cesarean section, uterine infection, perineal injuries and post partum hemorrhage) and fetus (macrosomia, birth injuries, meconium aspiration and stillbirth). Policies such as routine induction of labour between 40 and 42 weeks with strict intra partum monitoring may decrease in the incidence of these complications. The post term pregnancy adversely affects the maternal and fetal outcome with significant increase in the maternal and neonatal morbidity. The risk of fetus increases with increase in gestational age as found in the present study.

\section{Conclusion}

Management of pregnancy beyond 40 weeks upto 42 weeks remains controversial. Current research demonstrated that is increased in the risk for both mother and babies absolute risk of adverse event associated with gestational age. NICU admission one of the risk factors attributed to prolonged pregnancy.

Reduction in perinatal mortality is seen when caesarean section is done between 41 weeks and 42 weeks. In this complex clinical condition we should identify the foetus at risk and to institute an appropriate management following adequate counseling of patient.

So that when any pregnant women who comes in antenatal period or pre conception period should be counseled regarding the importance and necessity of accurate LMP so that we can reduce post dated pregnancy and its complications.
Funding: Nil, Conflict of interest: Nil

Permission from IRB: Yes

Ethical approval: Taken

What this study adds to existing knowledge?

In summary, post term pregnancy is associated with increased risks to both mother (cesarean section, uterine infection, perineal injuries and post partum hemorrhage) and fetus (macrosomia, birth injuries, meconium aspiration and stillbirth).

Policies such as routine induction of labour between 40 and 42 weeks with strict intra partum monitoring may decrease in the incidence of these complications. The post term pregnancy adversely affects the maternal and fetal outcome with significant increase in the maternal and neonatal morbidity.

So that when any pregnant women who comes in antenatal period or pre conception period should be counseled regarding the importance and necessity of accurate LMP so that we can reduce post dated pregnancy and its complications.

\section{References}

1. Treger M, Hallak M, Silberstein T, Friger M, Katz M, Mazor M. Post-term pregnancy: should induction of labor be considered before 42 weeks? J Matern Fetal Neonatal Med. 2002;11(1):50-3. DOI:10.1080/ jmf.11. 1.50 .53

2. Galal M, Symonds I, Murray H, Petraglia F, Smith R. Postterm pregnancy. Facts Views Vis Obgyn. 2012;4 (3): 175-87.

3. Divon MY, Haglund B, Nisell H, Otterblad PO, Westgren M. Fetal and neonatal mortality in the postterm pregnancy: the impact of gestational age and fetal growth restriction. Am J Obstet Gynecol. 1998;178 (4):726-31. DOI:10.1016/s0002-9378(98)70482-x

4. Olesen AW, Westergaard JG, Olsen J. Perinatal and maternal complications related to postterm delivery: a national register-based study, 1978-1993. Am J Obstet Gynecol. 2003; 189 (1): 222-7. DOI:10.1067/mob.2003. 446

5. Sanchez-Ramos L, Olivier F, Delke I, Kaunitz AM. Labor induction versus expectant management for postterm pregnancies: a systematic review with metaanalysis. Obstet Gynecol. 2003;101(6):1312-8. 


\section{Original Research Article}

6. Crowley P. Interventions for preventing or improving the outcome of delivery at or beyond term. Cochrane Database Syst Rev. 2000;(2):CD000170. DOI:10.1002/ 14651858.CD000170

7. Hannah ME, Hannah WJ, Hellmann J, Hewson S, Milner R, Willan A. Induction of labor as compared with serial antenatal monitoring in post-term pregnancy. A randomized controlled trial.The Canadian Multicenter Post-term Pregnancy Trial Group. N Engl J Med. 1992; 326 (24): 1587-92. DOI:10.1056/ NEJM 19920611326 2402

8. Campbell MK, Ostbye T, Irgens LM. Post-term birth: risk factors and outcomes in a 10-year cohort of Norwegian births. Obstet Gynecol. 1997;89(4):543-8.

9. Rand L, Robinson JN, Economy KE, Norwitz ER., Post-term induction of labor revisited. Obstet Gynecol. 2000;96(5 Pt 1):779-83.

10. MagramHM, Cavanagh WV. The problem of postmaturity: a statistical analysis. Am J Obstet Gynecol. 1960;79:216-23. DOI:10.1016/0002-9378(60) 90178-2

11. Lagrew DC, Freeman RK. Management of postdate pregnancy. Am J Obstet Gynecol. 1986;154 (1):8-13. DOI:10.1016/0002-9378(86)90384-4

12. Gardosi J, Vanner T, Francis A. Gestational age and induction of labour for prolonged pregnancy. $\mathrm{Br} \mathrm{J}$ ObstetGynaecol. 1997;104(7):792-7.

13. Crowley $\mathrm{P}$. Interventions for preventing or improving the outcome of delivery at or beyond term.
Cochrane Database Syst Rev. 2000;(2):CD000170. DOI:10.1002/14651858.CD000170

14. Cleary-Goldman J, Malone FD, Vidaver J, Ball RH, Nyberg DA, Comstock $\mathrm{CH}$, et al. Impact of maternal age on obstetric outcome. Obstet Gynecol. 2005; 105 (5 Pt 1):983-90. DOI:10.1097/01. AOG.00001 58118. 75532.51

15. Norwitz ER, Snegovskikh VV, Caughey AB. Prolonged Pregnancy:: When Should We Intervene?. Clinical obstetrics and gynecology. 2007;50(2):547-57.

16. Doherty L, Norwitz ER. Prolonged pregnancy: when should we intervene? CurrOpinObstet Gynecol. 2008; 20(6):519-27.

17. Evans M. Postdates pregnancy and complementary therapies. Complement Ther Clin Pract. 2009;15 (4): 220-4. DOI:10.1016/j.ctcp. 2009.09.002. Epub 2009 Oct 12 .

18. Eden RD, Gergely RZ, Schifrin BS, Wade ME. Comparison of antepartum testing schemes for the management of the postdate pregnancy. AmJObstet Gynecol. 1982;144(6):683-92.

19. Alexander JM, McIntire DD, Leveno KJ. Forty weeks and beyond: pregnancy outcomes by week of gestation. Obstet Gynecol. 2000;96(2):291-4.

20. Hilder L, Costeloe K, Thilaganathan B. Prolonged pregnancy: evaluating gestation-specific risks of fetal and infant mortality. BJOG: Int J Obstet Gynaecol. $1998 ; 105(2): 169-73$.

\section{How to cite this article?}

Golait S, Soni S. Maternal and perinatal outcome in pregnancy beyond expected date of delivery. Obs Rev: J obstet Gynecol 2019;5(3):161-168.doi:10.17511/joog.2019.i03.06. 